\title{
СТАТИСТИЧЕСКИЙ АНАЛИЗ ДИФФЕРЕНЦИАЦИИ СУБЪЕКТОВ РОССИЙСКОЙ ФЕДЕРАЦИИ ПО КАЧЕСТВУ ЖИЗНИ НАСЕЛЕНИЯ
}

\author{
() 2019 Фахрутдинова Елена Валерьевна \\ Казанский (Приволжский) федеральный университет, Респ. Татарстан, Казань \\ E-mail: efahr@mail.ru \\ (c) 2019 Камашева Анастасия Васильевна \\ Казанский (Приволжский) федеральный университет, Респ. Татарстан, Казань \\ (c) 2019 Валеев Эмиль Рамилевич \\ Казанский (Приволжский) федеральный университет, Респ. Татарстан, Казань
}

В статье проводится анализ дифференциации субъектов Российской Федерации по качеству жизни населения на основе статистических характеристик. Для обработки датасета пространственных данных, в котором объектами наблюдений выступают 85 субъектов РФ в период с 2015 г. по 2018 г., был использован программный продукт Gretl. Для решения поставленной задачи был использован аналитический инструментарий гипотезы нормального распределения выборочной совокупности объектов. Тестирование данной гипотезы показало, что данные выборки распределены по нормальному закону. Результаты статистического анализа продемонстрировали, что, с одной стороны, большая часть субъектов РФ отличается по качеству жизни незначительно. Вероятность попадания в этот доверительный интервал субъектов РФ, измеряемая частотой, составляет от 72,94\% до .76,47\%, что превышает статистически установленную величину в 68,26\%. Однако, с другой стороны, стандартное отклонение по выборке значительно. Число субъектов РФ с качеством жизни ниже среднего уровня по Российской Федерации во все годы выбранного периода исследования превышает число субъектов РФ с качеством жизни выше среднего уровня. Проведенный статистический анализ показал высокую эффективность применяемого статистического инструментария и предложенных критериев по оценке степени гомогенности отечественных регионов по качеству жизни.

Ключевые слова: качество жизни, региональная экономика, нормальный закон распределения, стандартное отклонение.

Выступая целевым показателем социально-экономического развития национальных экономик, качество жизни населения является платформой интеграции стратегий развития на региональном и локальном уровнях. Субъекты Российской Федерации неоднородны по качеству жизни населения. «Разброс между разными регионами по качеству жизни сейчас очень серьезен»*. В соответствии с рейтингом российских регионов по качеству жизни в 2018 г. рейтинговый балл г. Москва, занимавшей первую позицию, составлял 77.371 баллов. В то время как рейтинговый балл Республики Тыва, занявшей последнее 85-е место, был равен всего лишь 16.195 , что в 4,8 раза ниже по сравнению с Москвой (таблица 1) при медиане ряда рейтинговых баллов равной 46,51 и стандартном отклонении 10,92, что свидетельствует о значительном разбросе значений в представленном датасете баллов (таблица 2).

Неоднородность субъектов РФ по качеству жизни приводит к большим потерям в масштабе страны в результате экономически неоправданных финансовых, капитальных и миграционных потоков, несбалансированного территориального размещения производительных сил, обострения социальной напряженности и т.д.

«Проблема улучшения качества жизни в регионах России является приоритетной задачей руководства страны. Это вполне закономерно, поскольку резкий разрыв в условиях жизни людей только на том основании, что они проживают на разных участках ее территории, является недопустимым»**. Необходимо разрабатывать

\footnotetext{
* «Нет ни у кого такой задачи - уволить губернатора». Министр экономики о новой системе оценки работы глав регионов. - URL: https://www.kommersant.ru/doc/3960042, свободный

** Рейтинг российских регионов по качеству жизни - 2015. С. 3.- URL: www.riarating.ru//, свободный
} 
Таблица 1. Рейтинг российских регионов по качеству жизни в 2015-2018 гг."

\begin{tabular}{|l|c|c|c|c|c|}
\hline \multirow{2}{*}{\multicolumn{1}{c|}{ Субъект РФ }} & \multicolumn{3}{|c|}{ Рейтинговый балл } \\
\cline { 2 - 6 } & 2015 & 2016 & 2017 & 2018 & $\begin{array}{c}\text { Место в рей- } \\
\text { тинге 2015- } \\
2018 \text { гг. }\end{array}$ \\
\hline г. Москва & 76.23 & 76.54 & 76.92 & 77,371 & 1 \\
\hline г. Санкт-Петербург & 75.63 & 76.49 & 75.88 & 75,687 & 2 \\
\hline Московская область & 67.58 & 68.55 & 70.55 & 72,453 & 3 \\
\hline Республика Татарстан & 63.89 & 63.12 & 65.59 & 66,147 & 4 \\
\hline Республика Тыва & 12,63 & 12,53 & 13,96 & 16,195 & 85 \\
\hline
\end{tabular}

* Рейтинг российских регионов по качеству жизни - 2015.- URL: www.riarating.ru//, свободный Рейтинг российских регионов по качеству жизни - 2016. - URL: www.riarating.ru//, свободный Рейтинг российских регионов по качеству жизни - 2017. - URL: www.riarating.ru//, свободный Рейтинг российских регионов по качеству жизни - 2018.- URL: www.riarating.ru//, свободный

Таблица 2. Описательные статистики рядов рейтинговых баллов российских регионов по качеству жизни в 2015-2018 гг.

\begin{tabular}{|l|c|c|c|c|}
\hline & 2015 & 2016 & 2017 & 2018 \\
\hline Среднее (m) & 43,62 & 43,96 & 45,12 & 46,37 \\
\hline Медиана & 44,60 & 44,06 & 45,49 & 46,51 \\
\hline Стандартное отклонение (б) & 11,50 & 11,21 & 11,42 & 10,92 \\
\hline Дисперсия выборки & 132,32 & 125,66 & 130,50 & 119,33 \\
\hline Минимум & 12,63 & 12,53 & 13,96 & 16,20 \\
\hline Максимум & 76,23 & 76,54 & 76,92 & 77,37 \\
\hline
\end{tabular}

стратегию, нацеленную на снижение разрывов в качестве жизни населения субъектов РФ. Стратегическая установка на снижение степени дивергенции в траекториях развития субъектов РФ, приводящая к уменьшению неравенства в качестве жизни в отдельных российских регионах будет способствовать сбалансированному территориальному развитию России. Конечно, речь не идет о нивелировании всех имеющихся разрывов и межрегиональных различий. Специфика качества жизни в субъектах РФ обусловлена рядом объективных факторов, устранить действие которых неподвластно ни региональным, ни федеральным властям. Межрегиональные различия определены климатически, пространственно и современными особенностями государственного устройства. Но улучшить текущее состояние и уменьшить межрегиональные диспропорции в качестве жизни возможно.

Предварительным этапом реализации дан- ной стратегии выступает детальная диагностика текущих состояний и причин региональных разрывов и сложившихся диспропорций в качестве жизни населения в регионах России на основе статистических характеристик. Для обработки датасета пространственных данных, в котором объектами наблюдений выступали 85 субъектов РФ в фиксированные периоды времени, был использован программный продукт Gretl. B качестве временного интервала был выбран период с 2015 г. по 2018 г.

Для решения поставленной задачи был использован аналитический инструментарий гипотезы нормального распределения выборочной совокупности субъектов РФ. Результаты проверки данной гипотезы представлены на графиках распределения частот (рис. 1а - 1г).

Эффективным способом проверки данной гипотезы выступает анализ р-значений (value) вероятности ошибки при отклонении нулевой 


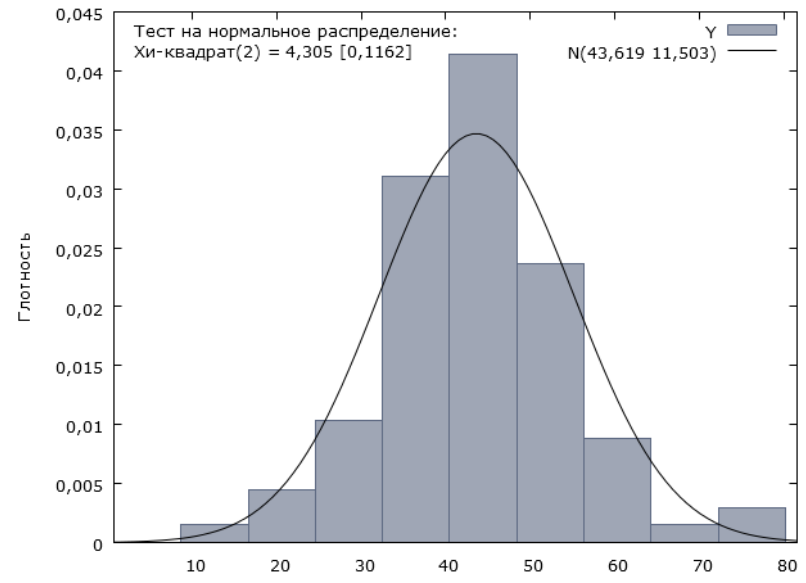

Нулевая гипотеза - нормальное распределение: Хи-квадрат(2) = 4,305 р-значение 0,11617

Рис. 1а. График функция плотности нормального распределения субъектов РФ по данным рейтинга качества жизни за 2015 г.

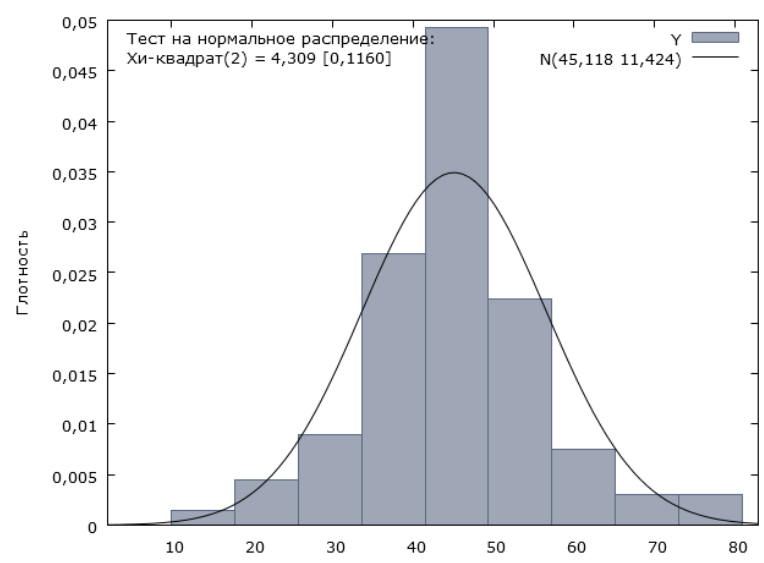

Нулевая гипотеза - нормальное распределение: Хи-квадрат(2) = 4,309 р-значение 0,11595

Рис. 1в. График функция плотности нормального распределения субъектов РФ по данным рейтинга качества жизни за 2017 г.

гипотезы. Для всех лет периода наблюдений p-значение больше, чем уровень значимости 0,05. Таким образом, данные выборки распределены по нормальному закону, т.е. эмпирические и теоретические частоты различаются незначительно.

Исходя из этого предположим, что на данной статистической выборке действует закон больших чисел, который применительно к качеству жизни в субъектах РФ можно сформулировать

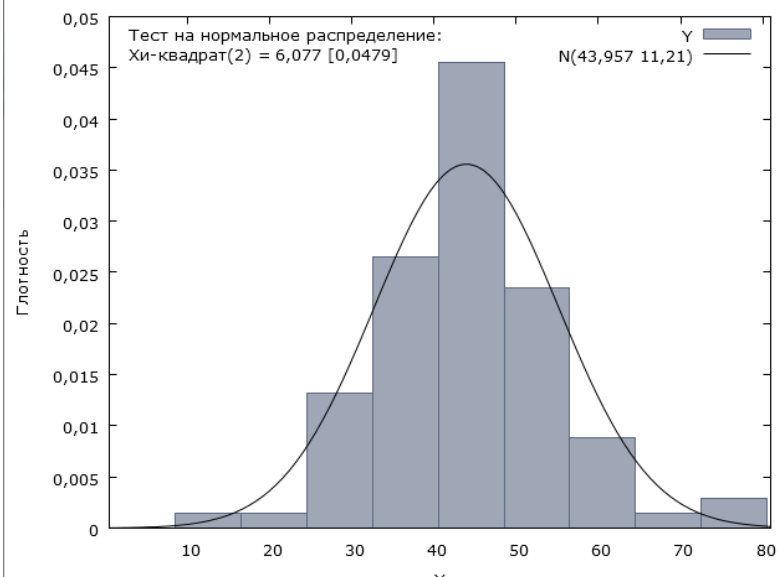

Нулевая гипотеза - нормальное распределение: Хи-квадрат(2) = 6,077 р-значение 0,04791

Рис. 1б. График функция плотности нормального распределения субъектов РФ по данным рейтинга качества жизни за 2016 г.

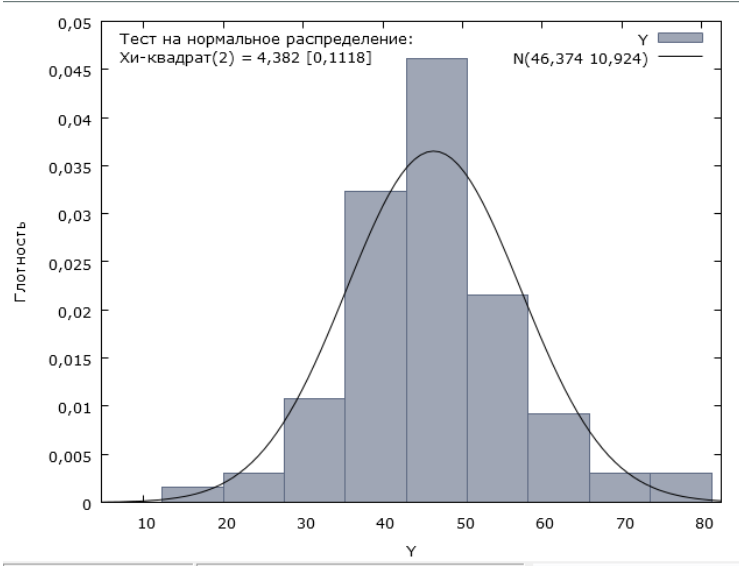

Нулевая гипотеза - нормальное распределение: Хи-квадрат(2) = 4,382 р-значение 0,11180

Рис. 1г. График функция плотности нормального распределения субъектов РФ по данным рейтинга качества жизни за 2018 г. следующим образом. Качество жизни населения в Российской Федерации является интегральной составляющей большого числа факторов отдельных аспектов качества жизни в субъектах РФ, влияние каждого из которых на интегральную оценку качества жизни в РФ незначительно. Если учесть, что при составлении рейтинга качества жизни в регионах РФ учитывались 73 разных показателя, то закономерно предположить, что средние результаты большого числа наблю- 
дений относительно устойчивы и мало зависят от результатов отдельных наблюдений. По сути, формируемый рейтинг интегрирует совокупное действие большого числа случайных факторов, что приводит к результату, почти не зависящему от случая.

Результаты статистического анализа продемонстрировали, что, с одной стороны, большая часть субъектов РФ отличается по качеству жизни незначительно (значения рейтинга находятся в доверительном интервале $(\mathrm{m}-\sigma ; \mathrm{m}+\sigma))$. Вероятность попадания в этот доверительный интервал субъектов РФ, измеряемая частотой, составляет от $72,94 \%$ до $76,47 \%$, что превышает статистически установленную величину в $68,26 \%$. Однако, с другой стороны, встает вопрос о норме стандартного отклонения. Очевидно, что чем меньше стандартное отклонение (мера разброса значений), тем выше уровень гомогенности субъектов РФ по качеству жизни населения. Положительным является факт, что хотя стандартное отклонение по выборке значительно, но постепенно уменьшается с 2015 по 2018 гг. Также наглядно видно, что число субъектов РФ с качеством жизни ниже среднего уровня по Российской Федерации во все годы выбранного периода исследования превышает число субъектов РФ с качеством жизни выше среднего уровня.

Воспользуемся правилом «трех сигм» $(3 \sigma)$, согласно которому практически все значения (99,73\%) нормально распределенной случайной величины входят в интервал $(2 \sigma+\mathrm{m} ; 3 \sigma+\mathrm{m})$. В нашем случае все $100 \%$ значений балльного рейтинга качества жизни в субъектах РФ уклады- ваются в этот интервал длиной $6 \sigma$ (таблица 3). Однако в другом заданном интервале продолжительностью $4 \sigma:(-2 \sigma+\mathrm{m} ; 2 \sigma+\mathrm{m})$ должно оказаться 95,44\% всех объектов, тогда как в нашей выборке их доля меньше. Если в качестве критерия нормы использовать правило «двух сигм», то в критическую область значений рейтинга качества жизни: $(-3 \sigma+\mathrm{m} ;-2 \sigma+\mathrm{m})$ и $(2 \sigma+\mathrm{m} ; 3 \sigma+\mathrm{m})$ попадает большее число субъектов РФ, чем по закону нормального распределения. В частности, в группу субъектов РФ, находящихся в критической области значений справа по оси значений рейтинга по закону нормального распределения устойчиво входят г. Москва, г. Санкт-Петербург, Московская область. В то время как Республика Тыва, Карачаево-Черкесская Республика (2018 г.) и Республика Ингушетия (2015-2017 гг.) образуют устойчивую группу субъектов РФ, попадающих в крайний левый интервал $(-3 \sigma+m ;-2 \sigma+m)$.

В соответствии с логикой закона нормального распределения чем меньше стандартное отклонение, тем короче доверительный интервал. Следуя данной логике, применим в качестве критерия удовлетворительного уровня гомогенности субъектов РФ по качеству жизни значение стандартного отклонения по ограниченной и более гомогенной выборке из 63 субъектов РФ, находящихся в доверительном интервале (m- $\sigma$; $\mathrm{m}+\sigma)$. Описательные статистики для этой гомогенной выборки представлены в таблице 4 и на рисунке 2.

Следовательно, для достижение данного целевого уровня стандартного отклонения в 5,56778 по данной гомогенной выборке необхо-

Таблица 3. Распределение субъектов РФ по доверительным интервалам

\begin{tabular}{|c|c|c|c|c|c|c|}
\hline Интервал & $\begin{array}{l}(-3 \sigma+m \\
-2 \sigma+m)\end{array}$ & $\begin{array}{l}(-2 \sigma+m \\
-\sigma+m)\end{array}$ & $(-\sigma+m ; m)$ & $(\mathrm{m} ; \sigma+\mathrm{m})$ & $(\sigma+\mathrm{m} ; 2 \sigma+\mathrm{m})$ & $\begin{array}{l}(2 \sigma+m \\
3 \sigma+m)\end{array}$ \\
\hline Частота в 2015 г. & 2 & 9 & 28 & 35 & 8 & 3 \\
\hline Частота в 2016 г. & 2 & 9 & 30 & 35 & 6 & 3 \\
\hline Частота в 2017 г. & 2 & 9 & 29 & 33 & 9 & 3 \\
\hline Частота в 2018 г. & 2 & 10 & 41 & 22 & 7 & 3 \\
\hline Интервал & \multicolumn{2}{|c|}{$(-\sigma+\mathrm{m} ; \sigma+\mathrm{m})$} & \multicolumn{2}{|c|}{$(-2 \sigma+m ; 2 \sigma+m)$} & \multicolumn{2}{|c|}{$(-3 \sigma+m ; 3 \sigma+m)$} \\
\hline \begin{tabular}{|l|} 
Доля объектов \\
2015 г. в интервале
\end{tabular} & \multicolumn{2}{|c|}{$74,12 \%$} & \multicolumn{2}{|c|}{$94,12 \%$} & \multicolumn{2}{|c|}{$100 \%$} \\
\hline $\begin{array}{l}\text { Доля объектов } \\
2016 \text { г. в интервале }\end{array}$ & \multicolumn{2}{|c|}{$76,47 \%$} & \multicolumn{2}{|c|}{$94,12 \%$} & \multicolumn{2}{|c|}{$100 \%$} \\
\hline \begin{tabular}{|l|} 
Доля объектов \\
2017 г. в интервале
\end{tabular} & \multicolumn{2}{|c|}{$72,94 \%$} & \multicolumn{2}{|c|}{$94,12 \%$} & \multicolumn{2}{|c|}{$100 \%$} \\
\hline $\begin{array}{l}\text { Доля объектов } \\
2018 \text { г. в интервале }\end{array}$ & \multicolumn{2}{|c|}{$74,12 \%$} & \multicolumn{2}{|c|}{$94,12 \%$} & \multicolumn{2}{|c|}{$100 \%$} \\
\hline
\end{tabular}


Таблица 4. Описательная статистика, использованы наблюдения 1-63 для переменной Y (63 наблюдений)

\begin{tabular}{|c|c|c|c|}
\hline Среднее & Медиана & Минимум & Максимум \\
\hline 46,5463 & 46,6500 & 37,6090 & 58,1480 \\
\hline Ст. откл. & Вариция & Асимметрия & Эксцесс \\
\hline 5,56778 & 0,119618 & 0,292420 & $-0,803282$ \\
\hline $5 \%$ Проц. & $95 \%$ Проц. & IQ range & $\begin{array}{c}\text { Пропущенные } \\
\text { наблюдения }\end{array}$ \\
\hline 38,8036 & 56,5980 & 8,29600 & 0 \\
\hline
\end{tabular}

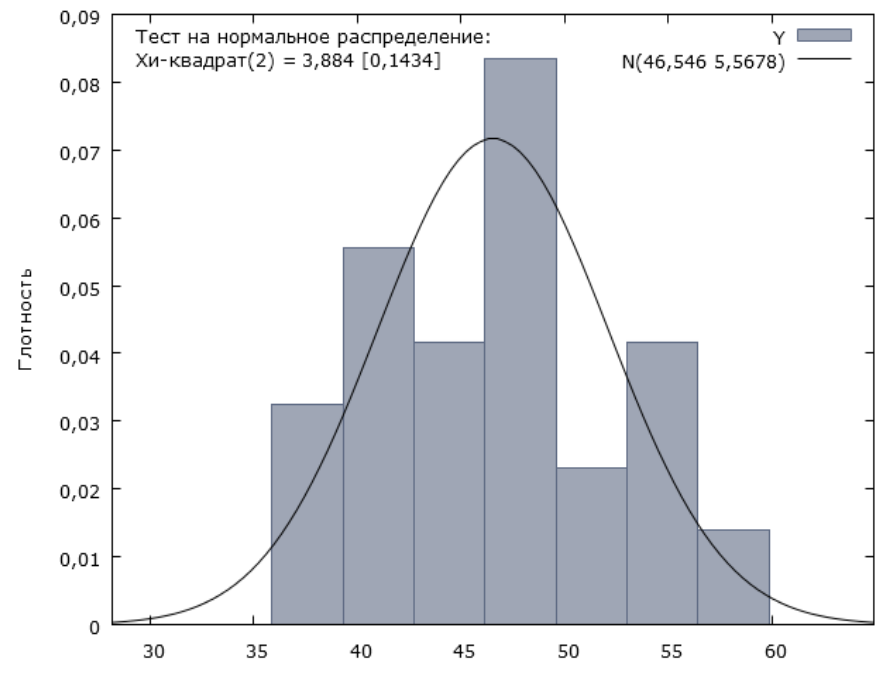

Нулевая гипотеза - нормальное распределение: Хи-квадрат(2) = 3,884 р-значение 0,14339

Puc. 2. График функция плотности нормального распределения субъектов РФ по данным рейтинга качества жизни за 2015-2018 гг.

димо уменьшить разброс значений факторных показателей в исходной выборке из 85 субъектов РФ примерно вдвое.

Показатели, используемые для построения рейтинга российских регионов по качеству жизни, практически полностью совпадают с критериями оценки эффективности деятельности высших должностных лиц субъектов РФ Российской Федерации (таблица 5). Эти критерии отражают «качество жизни в регионах и качество развития экономики. Экономика - это инвестиции и рабочие места, качество жизни - это здравоохранение, образование, дороги, качество среды в самом широком смысле»**

Поэтому в качестве прогнозных значений на 2024 года по качеству жизни населения можно использовать датасет, содержащий данные установленных целевых значений критериев эффективности деятельности высших должностных лиц субъектов РФ Российской Федерации до 2024 г.

Проведенный статистический анализ показал высокую эффективность применяемых методик и предложенных критериев по оценке степени гомогенности по качеству жизни отечественных регионов. Для построения прогноза рейтинга качества жизни в субъектах РФ в 2024 г. воспользуемся установленными прогнозными значениями одного из ключевых показателей оценки эффективности деятельности высших должностных лиц субъектов Российской Федерации - темпами роста реальной среднемесяч-

* 26 апреля президентом подписан указ № 193 «Об оценке эффективности деятельности высших должностных лиц субъектов РФ». Газета «Коммерсантъ» № 76 от 29.04.2019, с. 1. 
Таблица 5

\begin{tabular}{|c|c|c|c|}
\hline № & $\begin{array}{l}\text { Группы показателей рейтинга } \\
\text { российских регионов по каче- } \\
\text { ству жизни }\end{array}$ & № & $\begin{array}{l}\text { Показатели для оценки эффективности деятельности высших } \\
\text { должностных лиц (руководителей высших исполнительных } \\
\text { органов государственной власти) субъектов Российской Федера- } \\
\text { ции и деятельности органов исполнительной власти субъектов } \\
\text { Российской Федерации" }\end{array}$ \\
\hline 1 & Уровень доходов населения & 1 & $\begin{array}{l}\text { - Уровень реальной среднемесячной заработной платы (2017 } \\
\text { год - базовое значение). } \\
\text { - Уровень реальной среднемесячной заработной платы, в \% к } \\
\text { пред. году. } \\
\text { - Уровень бедности, \%. }\end{array}$ \\
\hline 2 & $\begin{array}{l}\text { Занятость населения и рынок } \\
\text { труда }\end{array}$ & 2 & Отсутствует соответствующий показатель \\
\hline 3 & Жилищные условия населения & 3 & $\begin{array}{l}\text { - Количество семей, улучшивших жилищные условия, тыс. } \\
\text { семей } \\
\text { - Уровень доступности жилья,\% }\end{array}$ \\
\hline 4 & Безопасность проживания & 4 & Доля городов с благоприятной городской средой,\% \\
\hline 5 & Демографическая ситуация & 5 & Естественный прирост населения, на 1 тыс. человек \\
\hline 6 & $\begin{array}{l}\text { Экологические и климатиче- } \\
\text { ские условия }\end{array}$ & 6 & Качество окружающей среды \\
\hline 7 & $\begin{array}{l}\text { Здоровье населения и уровень } \\
\text { образования }\end{array}$ & 7 & $\begin{array}{l}\text { - Ожидаемая продолжительность жизни при рождении, лет. } \\
\text { - Уровень образования. } \\
\text { - Уровень образования (2018 год - базовое значение) }\end{array}$ \\
\hline 8 & $\begin{array}{l}\text { Обеспеченность объектами } \\
\text { социальной инфраструктуры }\end{array}$ & 8 & Количество городов с благоприятной городской средой \\
\hline 9 & $\begin{array}{l}\text { Уровень экономического раз- } \\
\text { вития }\end{array}$ & 9 & $\begin{array}{l}\text { - Количество высокопроизводительных рабочих мест во вне- } \\
\text { бюджетном секторе экономики, тыс. человек } \\
- \text { Производительность труда в базовых несырьевых отраслях } \\
\text { экономики, индекс (2017 год - базовое значение) } \\
\text { - Объем инвестиций в основной капитал, за исключением ин- } \\
\text { вестиций инфраструктурных монополий (федеральные проек- } \\
\text { ты) и бюджетных ассигнований федерального бюджета, индекс } \\
\text { (2018 год - базовое значение) }\end{array}$ \\
\hline 10 & $\begin{array}{l}\text { Уровень развития малого } \\
\text { бизнеса }\end{array}$ & 10 & $\begin{array}{l}\text { Численность занятых в сфере малого и среднего предпринима- } \\
\text { тельства, включая ИП, тыс. чел. }\end{array}$ \\
\hline 11 & $\begin{array}{l}\text { Освоенность территории и } \\
\text { развитие транспортной инфра- } \\
\text { структуры }\end{array}$ & 11 & $\begin{array}{l}\text { Доля соответствующих нормативным требования автомобиль- } \\
\text { ных дорог регионального значения и автомобильных дорог в } \\
\text { городских агломерациях с учетом загруженности,\% }\end{array}$ \\
\hline
\end{tabular}

* Постановление Правительства Российской Федерации от 17 июля 2019 г. № 915

ной заработной платы в 2014 г. по отношению к 2017 году. В результате вычислений структура рейтинга по нашим оценкам в 2024 г. практически не изменится. Первые позиции останутся, как и прежде за г. Москва, г. Санкт-Петербург, Московской областью и Республикой Татарстан. Замыкать рейтинг будут Республика Ингушетия и Республика Тыва.

И это не случайно, т.к. установленные прогнозные темпы роста в основном повторяют уже сложившуюся структуру значений рейтинговых баллов качества жизни населения субъектов РФ на 2017 г. Диаграмма (рис. 3) наглядно демонстрирует, что намеченные темпы роста не компенсируют существующее отставание в рейтингах субъектов РФ по качеству жизни. На- пример, существенная разница в рейтингах Белгородской области (64) и Еврейской автономной области $(27,17)$, равная 36,93 баллам, не может быть уменьшена установленными прогнозными значениями темпов роста в 127,46\% для Белгородской области и 129,97\% для Еврейской автономной области.

В среднесрочной перспективе к 2024 году значительного уменьшения дифференциации субъектов Российской Федерации по качеству жизни населения ожидать не стоит при общем улучшении качества жизни в регионах. Текущая поляризация рейтинга, с большой степенью вероятности, не изменятся. Регионы-лидеры в социально-экономическом отношении будут иметь прежний высокий рейтинг качества жиз- 


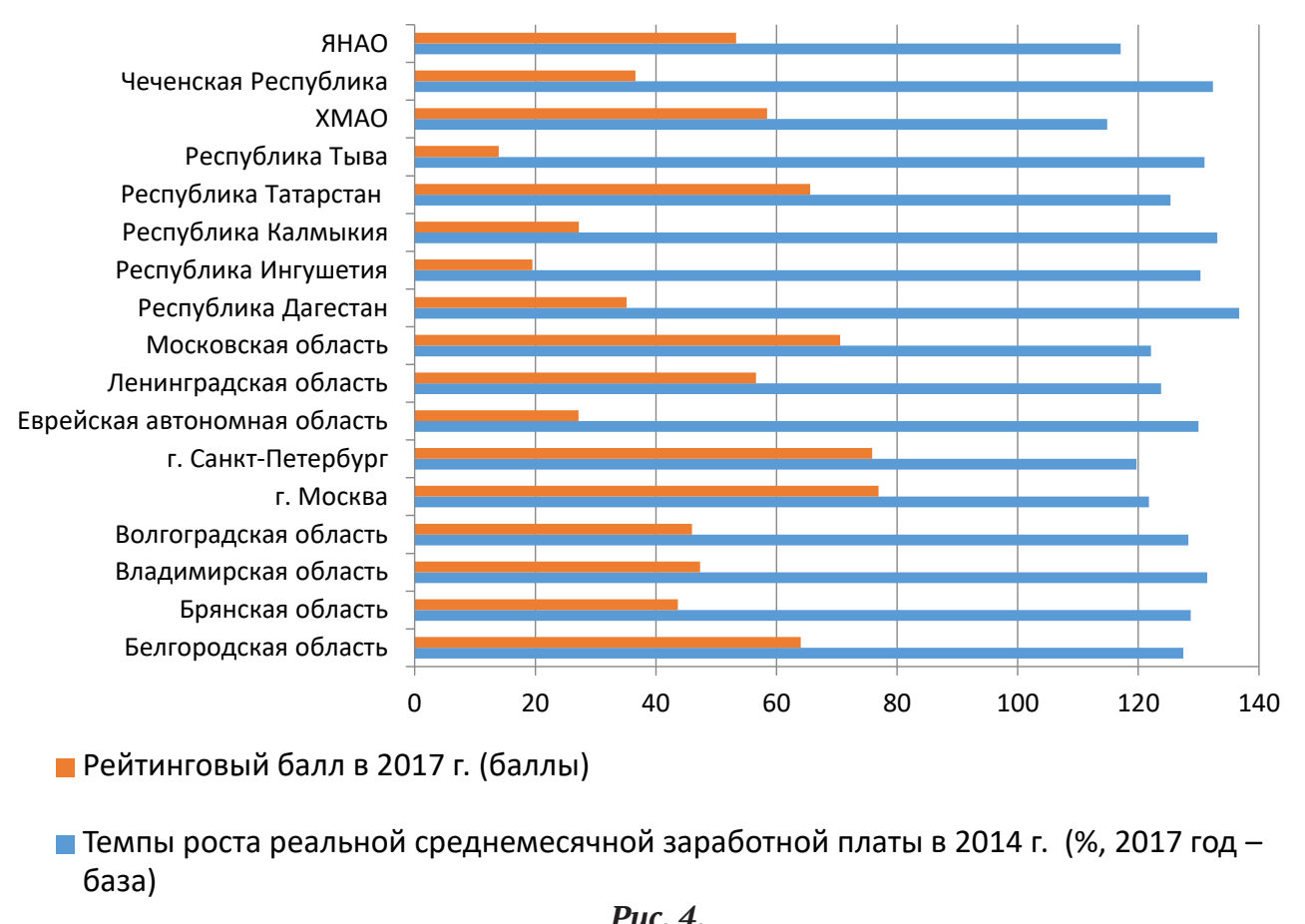

ни, в то время как субъекты РФ с дотационной экономикой останутся на низших позициях в рейтинге. Хотя в соответствии с установленными целевыми показателями в последних должны произойти соответствующие улучшения. Значительный прорыв в рейтинговых позициях возможно ожидать в следующих регионах, со-

ставляющих первую десятку по темпам роста реальной заработной платы: Республика Алтай, Республика Дагестан, Кабардино-Балкарская Республика, г. Севастополь, Республика Калмыкия, Кемеровская область, Карачаево-Черкесская Республика, Псковская область, Чеченская Республика и Республика Адыгея. 